\title{
LA RELEVANCIA DE LA HISTORIA COLONIAL EN EL MUNDO DE HOY
}

Mesa Redonda en la que participaron los profesores Víctor Álvarez M., Jorge Orlando Melo, Adolfo Meisel y Hermes Tovar, celebrada el 24 de abril de 1997 con motivo de la inauguración del Centro de Investigaciones de Historia Colonial.

HERMES TOVAR: En nombre del Instituto Colombiano de Cultura Hispánica y del Centro de Investigaciones de Historia Colonial, que hoy celebra con ustedes la iniciación de sus actividades y labores, agradezco su presencia y el deseo de compartir con nosotros los conocimientos y los aportes de tres invitados, que han venido de distintas partes del país para charlar en tomo a la relevancia de la historia colonial en el mundo de hoy. A continuación el doctor William Jaramillo, director del Instituto Colombiano de Cultura Hispánica y uno de los principales animadores de esta idea de convertir el Instituto en un Centro de Investigaciones y de apoyar toda política de recuperación de archivos, les va a dirigir algunas palabras y a dar por inauguradas nuestras actividades. Posteriormente escucharemos las intervenciones de los profesores Víctor Álvarez, Jorge Orlando Melo y Adolfo Meisel. Para

La transcripción fue realizada por Luís Enrique Rodríguez y Patricia Echeverri y editada por Marta Herrera Ángel, investigadores del Centro de Investigaciones de Historia. Colonial. finalizar, los panelistas responderán las preguntas que formulen los asistentes.

WILLIAM JARAMILLO: Muchas gracias profesor Tovar. Doctor Jorge Orlando Melo, doctor Adolfo Meisel, doctor Víctor Álvarez, doctor Luis Alarcón, doctor Hermes Tovar. En nombre del Instituto Colom- 
biano de Cultura Hispánica presento a ustedes un saludo muy cordial y les doy mi agradecimiento personal por su colaboración en este acto. El Instituto que ya cumple 46 años ha tenido como todas las cosas humanas altibajos en su vida. Cuando lo creó el doctor Laureano Gómez en 1951 fue quizás la Institución cultural más importante que había en aquel momento, por lo menos en Santa Fe de Bogotá. Tenía a su cargo muchas funciones. El Instituto promovía las conferencias, conciertos, exposiciones y era realmente el centro de agitación cultural de aquella provinciana, capital de hace 46 años. Era como un Colcultura o como el Ministerio de Cultura. Sin embargo, a medida que se fueron creando otras entidades, el Instituto fue perdiendo muchas de sus funciones. Cuando se creó la Biblioteca Luis Ángel Arango del Banco de la República, allí se empezaron a hacer las exposiciones; después se creó el Icetex, entidad que empezó a tramitar las becas con España y con otros países iberoamericanos, y así sucesivamente. Cuando se creó Colcultura, el Instituto perdió muchas más funciones. Adicionalmente el Instituto no siguió creciendo y en determinado momento se quedó con un objetivo sumamente grande y sin plata, sin personal. Quedó con un nombre muy importante, muy sonoro, pero sin funciones de ninguna categoría. A mí me enviaron a ver que hacía con él, si era mejor liquidarlo o transformarlo para adaptarlo a las nuevas circunstancias. Se me ocurrió la idea de que si era un Instituto de Cultura Hispánica, había que buscar esos orígenes y que estos estaban en el período colonial. Fue en ese período que llegó la cultura hispánica y se formó la cultura hispánica nuestra representada en el mestizaje. Sobre esta base pensé que lo que había que hacer era un centro de investigaciones del periodo colonial, para analizar nuestras raíces hispánicas. Estaba en esto, se cambiaron los estatutos del Instituto, pero no nos dieron recursos para realizar tamaña empresa. Con lo poco que pudimos recoger se empezaron unas investigaciones con muy buena voluntad pero con muy poco aliento, porque no teníamos los medios, ni los conocimientos, ni la técnica, para hacerlo.

En esta coyuntura nos conocimos con el profesor Tovar, no recuerdo quién nos presentó, pero fue muy interesante porque desde un principio hubo una empatía muy grande entre el profesor y yo. Coincidimos rápidamente en nuestras ideas y él empezó a participar en el proyecto. Primero nos trajo las tesis de grado de los estudiantes de la Universidad Nacional, con las cuales iniciamos una colección que se llama «Cuadernos de Historia Colonial», de la cual hasta el momento se han publicado cuatro obras. Sobre esta base se planteó la posibilidad de crear realmente el Centro de Historia Colonial, o sea darle vida a los estatutos del Instituto. Con esa idea, con las buenas relaciones del doctor Tovar y con todo su entusiasmo, hoy estamos prácticamente viendo las primeras realizaciones de ese sueño que tuvimos hace ya dos o tres años. Por eso, este Centro de Investigaciones de Historia Colonial del Instituto Colombiano de Cultura Hispánica, quiere ser un aula abierta para todos los 
interesados en la historia de Colombia, quiere ser la casa de los investigadores de historia del país, de sus universitarios, de sus profesores y de toda la intelectualidad que nos acompaña. De manera que declaro instalado el Centro de Investigaciones de Historia Colonial con esta mesa redonda, a la que les doy la bienvenida a todos, muchas gracias.

HERMES TOVAR: Muy amable doctor Jaramillo. Ustedes conocen muy bien a las tres personas que generosamente nos acompañan en el día de hoy. El Centro y el Instituto se sienten honrados con ellos. El profesor Adolfo Meisel es un investigador de los problemas económicos de Colombia y se preocupa también por la historia del siglo pasado y del período colonial. El profesor Víctor Álvarez, a quien ustedes igualmente conocen, se ha dedicado a la investigación histórica especialmente a la historia de Antioquia, aunque también tiene una tesis muy importante sobre México, que nunca ha querido publicar y no sabemos por qué. Y el profesor Jorge Orlando Melo, así mismo conocido por ustedes, es un investigador de los problemas de la política colombiana y de la historia colombiana no solamente del siglo XX, sino del siglo XIX y del período colonial. Él es además un escritor muy riguroso sobre los problemas de la historiografía y alguien que ha seguido muy de cerca la producción historiográfica nacional. Los tres nos expondrán sus ideas sobre la importancia de la historia colonial en el mundo de hoy, con el fin de analizar en esta mesa redonda la función que tiene para nosotros esa historia. ¿Por ejemplo, debemos seguir pensando que el mundo colonial es un espacio de reflexión marginal en la historia colombiana? Así mismo es importante interrogarnos sobre si en verdad nuestras investigaciones deben tener una proyección y una función mayor, es decir, si deben ir más allá de nuestro interés particular por el pasado.

Con la intervención del profesor Víctor Álvarez damos entonces comienzo a esta mesa redonda, luego hablará el profesor Meisel y a continuación el profesor Jorge Orlando Melo.

INTERVENCIÓN DE VÍCTOR ÁLVAREZ: Buenos días. En primer lugar quisiera agradecerle al profesor Hermes Tovar su invitación para participar en esta mesa redonda y el que él, junto con el doctor William Jaramillo, crearan este Centro de Investigaciones de Historia Colonial. Yo me atrevería a decir que se trata de una iniciativa que estuvo aplazada durante casi una generación y quiero empezar mi intervención refiriéndome a ello. Quienes tuvimos la feliz ocasión y en esta mesa somos tres- de aprender con Jaime Jaramillo Uribe lo que significaba el acercamiento a la vida colonial, iniciamos nuestra carrera como historiadores profesionales con una altísima preocupación por el mundo colonial. Lo hicimos no por accidente, sino por la tarea cumplida por él en este campo. Me 
atrevería a decir, un poco presuntuosamente, que esa generación de historiadores no sólo recibió de Jaime Jaramillo la sensibilidad, y la percepción sobre la importancia que tenía este campo de la historia, sino que no ha abandonado su tarea en ese frente. Tal vez eso pudo pensar Hermes cuando nos invitó, porque posiblemente mirando las preocupaciones que siguen en nuestras cabezas puede valorarse lo que significa un Instituto de este orden.

Aunque tengo un texto escrito, prefiero que esta charla tenga un carácter más informal y por ese motivo no leeré el texto. ${ }^{2}$ Uno ve que en Colombia ha crecido la preocupación por la historia, en la misma proporción en que crece la preocupación por la sociedad y por la crisis que se vive. No obstante, también se tiene la sensación de que desde otras disciplinas, desde la sociología, desde la ciencia política, la antropología y a veces desde posturas simplemente aficionadas, se diagnostica, se examina y se pronostica el desarrollo de esta sociedad sugiriendo que es una sola cosa: cambio. Se trata de una gran obsesión por el cambio, dentro de la cual se asume como fórmula permanente que todo ha cambiado y que todo viene cambiando. La gran obsesión por el cambio supone las posibilidades hasta de contrabandos. Se nos venden, por ejemplo, estudios sociológicos por análisis históricos. Es entonces el momento de preguntarnos ¿cuál es nuestro papel?. Y cuando digo nuestro, no me refiero a los historiadores, sino a la disciplina histórica.

Nuestro papel, nuestro asunto es el de la duración, vale la pena recordarlo y eso quiere decir el de las relaciones entre permanencia y cambio. Eso significa a su vez la posibilidad de contribuir en la construcción de la memoria colectiva, subrayando, las relaciones entre permanencia y cambio. Y, obvio es decir, que hay muchos elementos de la vida colectiva que son permanencias, que no están cambiando cada ocho días como se lo imaginan algunos jóvenes sociólogos y, además, que su permanencia es muy importante, ya que es eso lo que le da identidad a los pueblos. Y esos elementos de permanencia en un pueblo, en la historia de una comunidad, no son de construcción corta, suelen ser -para utilizar una expresión tal vez inadecuada en este contexto-, asuntos de larga duración. Entender la sociedad de hoy en Colombia implica preguntarse también por los asuntos de larga duración, que se remontan varios siglos, que significan perdurabilidades y que significan, entonces, sellos difícilmente modificables. Pero como eso no ha ocurrido en los últimos quince años pareciera que no existe.

Cuando uno mira la realidad, e incluso, de alguna manera en el clima que se mueve cuando se habla de la época colonial, uno descubre que seguimos pegados de una pelea que empezó por allá, en el mismo momento de la conquista. El acercamiento

2 El texto escrito de la exposición del profesor Víctor Álvarez se incluyó en el presente número de la revista, en la sección de articulas. 
que solemos hacer a la vida colonial sigue sellado por el cuento de los buenos y los malos, de si fue bueno o si fue malo, de cuáles son los buenos y cuáles son los malos. Con motivo de algo que yo, públicamente, llamé la piñata de los quinientos años, volvimos a vivir lo mismo. Como que el escenario servía no para comprender los procesos cumplidos a partir de la conquista, sino para volver a hacer el discurso de buenos y malos, de pobrecitos, de destruidos, de construidos, de relegados. Al reflexionar sobre esas cosas me encuentro con la idea de aportar algo en la construcción de esta senda, que Hermes ya ha empezado a pensar muy sensatamente invitándonos, como lo hizo recientemente, a pensar en la relación entre colonialismo y diversidad.

Con la idea de someter a evaluación un tema, a uno se le ocurre pensar que vale la pena replantear en una perspectiva grande lo que significa el acercamiento a los asuntos coloniales y replantearlo quiere decir reconocer una realidad cultural distinta de la que ha presidido todas esas preocupaciones. Noten que lo dominante sigue siendo suponer algo así como que somos europeos. Entonces dentro de nuestra versión sobre la vida colonial se hace la pregunta sobre qué es lo que nos acerca, qué es lo que nos hace valiosos a partir de lo europeo. O somos indios, y entonces los europeos vinieron y nos hicieron, nos quitaron, nos destruyeron, nos maltrataron. $\mathrm{O}$ somos negros y entonces nos esclavizaron, etc. Nos olvidamos de que la gran mayoría de la población latinoamericana, y en este país, la gran mayoría de población es otra cosa que no es ni indio, ni negro, ni blanco, es mestizo. Y entonces no nos damos del todo cuenta de qué significa dirigirse a mirar la vida colonial a partir del reconocimiento de que allá están nuestros orígenes.

Una pequeña anécdota solamente, porque en el texto está ilustrada con algún detalle. Prevalece en nuestro medio, incluso en el medio instruido, la noción de que las relaciones de intercambio entre blancos e indios fueron necesariamente violentas, y como el asunto es quién es el bueno, quién es el malo, nos hemos negado, sistemáticamente, a examinar cómo fue la colaboración de indios con españoles, porque eso no puede ser, eso no pudo existir.

Con motivo de la piñata de quinientos años, yo contaba sobre muchos casos de mujeres indígenas que se enamoraron de los españoles y alguna señora, mujerista, muy furiosa, me dijo que era el colmo, que cómo iba a decir eso, si lo único que había ocurrido era que los españoles habían violado a las indias. Bueno, tuve que explicarle que ocurren casos en que algunas mujeres se enamoran de los hombres $y$, para que me pudiera entender lo que pasó con los españoles, que está en los testimonios de la época, me tocó apelar a decirle que si hoy se enamoraban de los policías, por qué no entender que se enamoraran de los españoles. 
No obstante, esas imágenes siguen presentes. Esa primera comunicación de españoles e indígenas, produce unos resultados. Uno, de los muchos, fue la aparición de un producto nuevo que son los mestizos. Tan nuevo y tan importante que desde el propio siglo XVI se reconocieron como diferentes, que desde el propio siglo XVI, bueno, muchos de ellos se articularon a las aventuras de sus propios padres y se volvieron capitanes de empresas conquistadoras; algunos hasta recibieron encomiendas. Examinando alguna vez el catálogo de pasajeros a Indias, mi primera sorpresa fue ver que a partir de 1560 empiezan a registrarse mestizos que vienen para América, y me puse a hacer la cuenta de cuántos venían para el Nuevo Reino y sorprende el número. Sólo en un año, y lo menciono de memoria porque lo acabo de mirar, en 1567, sólo en ese año se registraron para venir al Nuevo Reino catorce mestizos, y si ustedes piensan que en ese catálogo no hay un seguimiento sistemático, uno se sorprende. Lo cierto es que ese producto está ahí. Que se va a diferenciar, que ya no son blancos, ya no son españoles, ni siquiera pueden pretender ser criollos y ese producto va en crecimiento, de muy diversas maneras. Es un lugar común saber que a donde quiera que iban las huestes de conquista iban acompañadas de cientos de mujeres indígenas. Incluso hay un relato según el cual la expedición de Belalcázar que vino a Santafé trajo yo no sé cuántas y que había uno que negociaba, porque usaba las mujeres como proxeneta. Y, en muchas partes, hubo convivencia de los blancos, los primeros blancos españoles, con esas mujeres indígenas y eso quiere decir que hubo muchos hijos.

En un trabajo reciente, de un historiador santandereano, leí que en Pamplona, en 1577, se contaban doce artesanos. Oigan, tan temprano como en 1577, había doce artesanos mestizos. Esos primeros mestizos nos dejan conocer algunas cosas. La primera es que, bueno, son un encarte para la sociedad colonial constituida. Una sociedad cuyos parámetros institucionales y mentales están pensados en función de blancos, indios y negros. La primera expresión de ese encarte es una real cédula de 1567 que prohíbe que se mezclen con los indios, argumentando que esos mestizos son perversos, viciosos, que son causa de los males de los indios. Se empieza así a construir una imagen que lo va diferenciando cada vez más y que corre pareja con una realidad demográfica, política y social, y es que esa población va en aumento.

Uno puede decir que en el siglo XVII se da un proceso de recuperación demográfica, pero fundamentalmente de la población mestiza. No con el vigor con que se va a recuperar en el siglo XVIII; pero después de la catástrofe demográfica, crece la población mestiza. Se trata de una población de mestizos que se encuentran en muy diversas situaciones. Y claro, como el siglo XVII es, se podría decir, el de la formación de sociedades mestizas y es tan poco interesante porque no hay tanto blanco, ni tanto indio, ni tanto negro violentado, ha sido un gran vacío en las preocupaciones de nuestra disciplina. 
Todavía se sigue trabajando en la construcción de una noción sobre nuestra historia en la que se destaca la conquista y luego se saltan dos siglos, para llegar a fines del siglo XVIII. Lo demás no existe. Doscientos años que siguen siendo parcialmente silenciados. Bueno, en esos doscientos años lo que está en el centro es la formación de las sociedades mestizas. En mi caso, que durante buena parte de mi vida me he dedicado a tratar de entender el desarrollo histórico de una región colombiana, no tengo ninguna duda que, específicamente para el caso de Antioquia, el siglo XVII es el siglo de los mestizos. A una sociedad esclavista conformada inicialmente, sucedió desde mediados del siglo XVII un pueblo de mestizos. Miren ustedes, cuando en 1675 se siguió todo el proceso para darle el sí o no a la villa de Medellín, el primer argumento que se dio fije que ese valle estaba lleno de más de mil mestizos y mulatos vagabundos, que no obedecían ni a los parámetros de los indios, ni de los negros, ni de los blancos. Y luego, la crisis minera precipita un proceso -tal vez el más temprano en este territorio- de manumisión de esclavos. Desde 1630 se vuelven negros libres y entran en un proceso permanente de intercambio con los otros grupos, y sí, más de la mitad de la población de ese valle de Aburra es de mestizos. Y mestizo quiere decir no sólo el producto genético del cruce indio, blanco, negro, quiere decir muchas otras cosas.

Empecemos por decir que mestizo quiere decir no indio, no negro y no blanco. Y eso significa mucho. Significa que no paga tributo, que no vive en comunidad, que no participa de las tierras de los resguardos ni de los pueblos indígenas, que no tiene doctrina, que no tiene escuelas, y en el texto me animo a decir que es como la cultura del no. Que, entonces, por no ser negro no está oprimido, es libre, no está obligado a trabajar en determinadas circunstancias, trabaja por su propia iniciativa y en labores que le garantizan su independencia. En el caso de Antioquia es el que empieza a colonizar desde el siglo XVII y a lavar oro como mazamorrero humilde, a ser carguero, a ser arriero, a ser pequeño mercader, tratante y artesano. Y, obvio, no es blanco y eso quiere decir que no participa de ninguna de las preeminencias, ni de los factores de poder, y sí, es objeto de permanente discriminación. Tanta que en la misma erección de Medellín en villa, el Cabildo, rapidito, rapidito dice que hay que sacarlos del marco de la plaza que ya estaba construida. Les quitan los solares, les mandan afuera para darle la plaza a los blancos y españoles que le den lustre -esa es la expresión- al marco de la plaza.

Ese es apenas un símbolo de lo qué ocurre. Pero bueno, todo eso que no es el mestizo, está acompañado de una cosa que sí es, pero perdón, tal vez antes debo enunciar otros no, para entender los sí. No tiene ninguna tradición cultural a que apelar por no ser indio, ni negro, ni blanco. Su única posibilidad es diferenciarse de los que le antecedieron y construir una forma de vivir, una forma de pensar, una forma de organizarse socialmente, que no corresponde a los parámetros de los tres 
paradigmas indio, negro, blanco. Y eso significa desde la vida cotidiana hasta las formas de constitución de la vida familiar. Eso significa que si el mestizo tenía un origen en relaciones ilegítimas (porque eso era, porque los españoles no se casaron con las indias, salvo uno que otro loquito como Julián Gutiérrez en Urabá y porque los blancos tampoco se casaron con las negras pero si tuvieron hijos), ese antecedente va a tener algún peso sobre las formas como construyó su vida familiar, pero sobre las cuales tenemos una absoluta ignorancia.

Cuando uno piensa en la cultura campesina colombiana y se pregunta qué tenemos en materia de estudios en los últimos cincuenta años, que nos den cuenta de cómo es la relación con el mestizaje, tiene que decir que todo el tiempo estamos tratando ver si son blancos o indios. Cuando uno pregunta por los comportamientos políticos, por la vida familiar, por muchas cosas de la mayoría de nuestra población, los puntos de referencia siguen siendo los blancos, los indios y los negros, porque imaginamos que no existe esa historia. Y es que eso que sabemos, que a fines del siglo XVIII en general dos terceras partes de la población de este territorio eran consideradas como de libres, (ciento veinte mil en la provincia de Tunja, cuarenta mil arrochelados que redujo en Cartagena Latorre Miranda, treinta y cinco mil de los cincuenta mil en Antioquia y así sucesivamente). Esto es como si no existiera para nosotros y seguimos imaginándonos que esos dos y medio siglos de historia no pasaron. No consideramos que esa gente tuvo que construir formas de alimentación, formas de convivencia, formas de relación familiar y hasta conductas políticas.

En ese sentido, y para no alargarme más, la propuesta para incorporar en la agenda como un asunto más, es la de volver los ojos sobre la colonia para estudiar también qué fue de verdad el asunto del mestizaje, porque todos estamos de acuerdo en que fue la época en que surgió el mestizaje. Lo acaba de decir el doctor William Jaramillo, pero ¿qué conocemos de verdad de cómo es el asunto? O si es sólo como nos enseñaron en la escuela -bueno, a mí me lo enseñaron ya en la universidad- que blanco con indio da mestizo y blanco con negro da mulato y negro con indio da zambo. Y luego vamos cruzando hasta que nos encartemos cuando nos aparezcan los saltatrás, tente en el aire, no te entiendo, jachivaro y bueno, todos esos términos que encontramos en la documentación, o como lo resolvieron en el siglo XVIII, libres de todos los colores. Entonces la pregunta es, cómo se construyó eso en términos de su desarrollo social, de sus formas culturales, de sus formas de integrarse a la sociedad, porque al final esa es la mayoría de la población colombiana. Gracias.

INTERVENCIÓN DE ADOLFO MEISEL: Un primer aspecto que me gustaría señalar es el relativo a divisiones tales como "historia colonial" o "historia republicana", a las que nos hemos acostumbrado en la historiografía y que si bien responden 
a algunas necesidades organizativas e incluso tienen alguna lógica desde el punto de vista de las bibliografías que se manejan, no tienen demasiada relevancia desde la perspectiva del oficio del historiador. Esto se hace más evidente cuando uno se hace preguntas centrales, como la que nos reúne hoy aquí. En realidad esa es una pregunta que se han planteado siempre los grandes maestros de la historia y por eso me gustaría empezar con una cita del historiador E. H. Carr que me parece muy apropiada. Dice Carr:

«La historia, como dijo Burckhardt, es el conjunto de lo que una época encuentra digno de atención en otra. El pasado nos resulta inteligible a la luz del presente y sólo podemos comprender plenamente el presente a la luz del pasado. Hacer que el hombre pueda comprender la sociedad del pasado e incrementar su dominio de la sociedad del presente, tal es la doble función de la historia».

Esa doble función, ese diálogo entre el pasado y el presente, es también lo que uno encuentra, por ejemplo, en Marc Bloch, en su libro póstumo sobre el oficio del historiador. Repasando ese trabajo se observa la importancia que le da a esta pregunta, con la que arranca ese libro escrito en las difíciles condiciones personales que vivía en 1941, cuando ya Francia había sido invadida y él y su familia como judíos corrían peligro. En últimas, la respuesta que le da a esa pregunta es que la historia sirve para establecer un diálogo entre el presente y el pasado, que ilumina a ambos. El pasado ilumina al presente y nos lo hace más comprensible y, de la misma forma, el presente ilumina el pasado y facilita su comprensión. Y esa es una tarea que nunca termina. Cada generación tiene que establecer ese diálogo y redefinir el pasado. En este sentido Lucien Febvre decía: «Cada época se fabrica mentalmente su representación del pasado, su Roma, su Atenas, su Edad Media y su Renacimiento», porque realmente ese pasado está siempre en función del presente. Quiero ilustrar con dos experiencias, cómo el presente ayuda tanto a iluminar al pasado como a enriquecer el presente.

Uno de esos temas es el de la Independencia. Para mi generación era un tema que despertaba poco interés, nos parecía aburrido y nos lo saltábamos. En el primer trabajo que hice deliberadamente establecí el corte cronológico en 1850, como para indicar que la colonia se prolongaba hasta esa fecha y sobre la Independencia sólo hice una mención muy de pasada. Y es que ese era el reino de la Academia de Historia, algo que a uno realmente lo tenía sin cuidado, plagado de héroes y sus luchas. Incluso recuerdo que en Cartagena, cuando de muchacho iba a cine, atravesaba por el Camellón de los Mártires y pasaba frente a los bustos de todos los héroes fusilados en 1815, cuando la reconquista de Morillo. Debajo de estos bustos, había siempre leyendas burlándose de estos próceres con un cinismo total, que mostraban lo que podía representar para las nuevas generaciones lo que fueron esas personas. 
Sin embargo, yo creo que si con las gentes de algún período histórico mi generación siente ahora cierta identificación, es precisamente con la generación que vivió la Independencia. En parte esta nueva percepción ha sido producto de las experiencias del movimiento regionalista costeño, que ha llevado a revaluar el papel de quienes participaron en la Independencia. Se han empezado a encontrar grandes afinidades en cuanto a los temas que se planteaban y, en últimas, con su visión del mundo. Esto ha sucedido, por ejemplo, con José Ignacio de Pombo, un comerciante cartagenero que fue de los pensadores económicos más lucidos que tuvo la Nueva Granada a finales del siglo XVIII. En su escritos, varios de ellos rescatados por el profesor Jorge Orlando Melo, se puede apreciar su preocupación por el desarrollo económico de las provincias de la costa Caribe colombiana, por su atraso, porque tenían unos niveles de exportaciones per cápita muy bajos en comparación con los de otras provincias del imperio hispánico y se planteaba mecanismos para lograr que eso cambiara. En algunas de sus argumentaciones se observa la incidencia que tuvieron sobre sus ideas las teorías de economistas como Adam Smith, como por ejemplo, la de la necesidad de elevar el nivel del capital humano, aumentar la competencia, mejorar la asignación de los recursos y reducir el nivel de los impuestos. Ideas que también se aprecian en la generación que vivió la Independencia, cuyo proyecto político era en el fondo crear un Estado en el cual se les diera participación. La participación en el Estado era la reivindicación central de los costeños que participaron en la Independencia, que veían que los españoles los desplazaban en este campo. Esa es también una de las grandes preocupaciones del regionalismo costeño en el siglo XX. En el último siglo, por ejemplo, no hemos tenido un presidente costeño. La participación de la Costa ha sido casi nula en la conducción de la política económica y en general en el manejo del Estado central, lo cual se refleja en bajos niveles de participación de la región en la inversión en infraestructura.

Al ser mirada la generación de la Independencia desde esta nueva perspectiva, los trabajos que se están haciendo sobre ese período la están reinterpretando. Esto se aprecia, por ejemplo, en el caso de Gustavo Bell, quien fue el primer gobernador del departamento del Atlántico elegido popularmente y quien ha estado muy involucrado en el movimiento regionalista costeño. Su visión sobre lo que fue la generación Independentista es completamente nueva. Se aprecia ya el interés y la empatía con los problemas que enfrentó esa generación y lo que antes nos parecía tan aburrido adquiere una nueva dimensión. Entonces, estoy seguro de que como resultado de los procesos que se están viviendo en la costa Caribe, de las preocupaciones regionalistas, se van a tener trabajos sobre el período de la Independencia desde una perspectiva completamente diferente y renovada. 
Otro ejemplo que pondría sobre cómo el presente nos ayuda a entender el pasado y viceversa, es el de lo que yo definiría como una identidad suprimida y que está en este momento en proceso de recuperación y de redefinición. Es el caso de la comunidad sefardita de Barranquilla. En un trabajo que en este momento está adelantando la doctora Adelaida Sourdís ha encontrado que muchos de los apellidos tradicionales barranquilleros y costeños son de origen judío, aunque no son percibidos como tales. Creo que Barranquilla es la única ciudad colombiana que tiene un aeropuerto con el nombre de un empresario judío: Ernesto Cortisoz. Todos esos apellidos de la comunidad sefardita hoy en día no son apellidos judíos porque esa comunidad fue completamente absorbida; son apellidos como Cortisoz, Salas, Sénior, Heilbron, Juliao, López- Peña o Álvarez-Correa. Esa es una parte de la identidad de la Costa que ha sido suprimida, porque en el momento que se dio la conversión se dio un intento por borrar ese pasado judío.

Cuando se empieza a rescatar ese pasado judío se encuentran cosas bastante curiosas. Por ejemplo, en un artículo de Adelaida Sourdís se muestra que los zurrones o empaques de cuero en que se enviaba a Bremen el tabaco de El Carmen de Bolívar, llevaban a menudo la estrella de David o símbolos cabalísticos que identificaban al exportador, pues casi todos esos exportadores eran judíos. Si este fenómeno se vincula con la importancia que ha tenido en la historia costeña el tabaco de El Carmen, se puede apreciar lo novedoso de esta situación, pues no es usual asociar a la Costa Caribe de Colombia con la estrella de David. En la medida en que se recupere esa identidad de la comunidad judía barranquillera, que forma parte esencial de lo que ha sido la historia de la Costa, habrá una mayor sensibilidad nuestra frente a toda, la historia del judaísmo. De esta manera se amplía la perspectiva de la historia local, y ahora la historia de Barranquilla y la Costa no será sólo su propia historia, sino que también será la historia del pueblo judío, lo que le dará un horizonte mucho más amplio y enriquecerá su identidad.

En fin, ejemplos de esta naturaleza abundan. Hay muchas otras "identidades suprimidas" que es importante tener en cuenta. Por ejemplo, no se tiene conciencia en la Costa de la importancia del elemento indígena dentro de la población, a pesar de que a lo largo del período colonial tuvo un peso demográfico muy grande. Incluso al finalizar la Colonia el $20 \%$ de la población era indígena y muchos de los llamados libres eran zambos o mestizos. Entre los campesinos del Sinú, por ejemplo, se puede observar que son más bien mestizos. Además, al adentrarse uno hacia el interior de la Costa se aprecia que aumenta la participación del elemento indígena.

En términos generales, se asocia mucho más la identidad de la Costa con el negro que con el indígena; sin embargo, en las áreas rurales de la costa el negro nunca 
tuvo una participación muy grande, en la medida en que no hubo una economía de plantación de importancia. Las grandes concentraciones de esclavos negros se presentaron en las zonas urbanas, no en las zonas rurales. En estas últimas se le ocupaba fundamentalmente cuidando ganado, en los trapiches y en el transporte. Es decir que se dio en la costa Caribe colombiana un tipo de sociedad muy distinta de lo que fue la sociedad esclavista del resto del Caribe, pues aquí se dieron unas relaciones de carácter más paternalista. En buena medida esto explica por qué en el Caribe colombiano las relaciones raciales fueron un poco más fluidas, ya que el grueso de la población esclava de la Costa estuvo vinculada a labores domésticas, es decir actividades urbanas y artesanales. En ese contexto las relaciones fueron menos rígidas que las que se dieron en las economías de plantación. La población esclava estaba más integrada, tanto con la población indígena en las zonas rurales, como con la población blanca en las zonas urbanas. El carácter de estas relaciones ayuda a entender los fenómenos de la identidad en el presente y permite establecer una especie de diálogo con otros períodos históricos que enriquece nuestra percepción del presente. Gracias.

INTERVENCIÓN DE JORGE ORLANDO MELO: La pregunta sobre si la historia resulta de utilidad para enfrentar los problemas de la sociedad, se ha constituido en una preocupación casi que permanente entre los estudiosos de esa disciplina. Cuando el profesor Tovar, el profesor Álvarez y yo jugábamos en el mismo equipo de fútbol en la Universidad Nacional, había una respuesta dominante a esta pregunta. Se trataba de un planteamiento que tenía una influencia mixta del positivismo y del marxismo, que vinculaba el conocimiento con la idea del desarrollo o del cambio social. Sobre esta base se daba lugar a dos respuestas derivadas de esta vinculación entre conocimiento y cambio social. La primera consistía en señalar que a partir del conocimiento de los procesos históricos se podía en cierta forma prever el futuro, lo cual resultaba de particular importancia al momento de tomar decisiones. La segunda, que era la que primaba entre la gente vinculada a la discusión sobre el modo de producción, partía de la inminencia de una revolución que transformaría radicalmente la sociedad y que se produciría como resultado del movimiento natural de la sociedad y más precisamente de su dinámica histórica. Entender el proceso histórico resultaba crucial dentro de esta perspectiva para adelantarse a los acontecimientos y tomar decisiones políticas acertadas, que facilitaran el proceso revolucionario que estaba por darse.

Con el tiempo se abandonó la idea de la inminencia de la revolución, así como la creencia de que el conocimiento ayudaba a prever el futuro. Ya no le otorgamos al conocimiento de la historia ese poder de predecir y, hasta cierto punto de transformar el futuro que se le otorgaba. Pero el problema de la relación entre historia y cambio siguió siendo importante. Y es que ya no pensamos en cambiar el futuro, 
sino el pasado y de alguna manera ese pasado cambió. Para apreciarlo basta con comparar los textos escolares. En ellos ya se reconoce, por ejemplo, la diversidad cultural. Incluso en los colegios que presentan deficiencias educativas, los textos que se utilizan muestran algo de esta diversidad. Ya aparecen en ellos los negros, los indios. Esta idea de variedad se constituye ya en un cambio, sobretodo si se compara con los tiempos en que Henao y Arrubla era el texto básico de enseñanza de historia. Recordemos que en ese libro sólo media página se dedicaba a los negros, aunque en su mayor parte de lo que trataba era de la obra de san Pedro Claver.

Este cambio, que ha tenido un impacto fuerte sobre el sector escolar y el clima social, coincidió con otros procesos sociales, en los que se ha visto reflejada esa nueva actitud frente a la diversidad. La nueva constitución, por ejemplo, reconoció los derechos de los indios y de las minorías. En la discusión histórica otra vez se vuelve a plantear como un problema central el del mestizaje y surgen múltiples preguntas sobre la forma como éste se vincula con la problemática social colombiana. Se busca entender si tiene algo que ver con la violencia y la intolerancia y no sólo desde la perspectiva de la historia. Por ejemplo, mi esposa que es psicóloga, trabaja una hipótesis sobre el mestizaje negado. Mira cómo el proceso de mestizaje fue fundamentalmente violento y observa que prima en la percepción de este fenómeno una perspectiva que se identifica con el violador, con la actitud de éste y que toma la vía de la intolerancia. Se presenta también la que se identifica con la persona violada, que se manifiesta en militancia.

Pero es necesario tener en cuenta que el estudio del mestizaje no es nuevo. Este se constituyó, por ejemplo, en un tema central dentro de las investigaciones del profesor Jaime Jaramillo U. Lo que ha cambiado es el concepto mismo del mestizaje y la identificación que se establece con el mismo. Algo similar ha sucedido también con el problema de la diversidad regional. Entonces, retomando el problema de la relación entre conocimiento y cambio social, se puede observar cómo la historia es autoconciencia y que es esa conciencia histórica la que incide en la transformación de la sociedad. Si bien el conocimiento de la historia no permite prever el futuro y hacer más confiable el proceso de toma de decisiones, si lo enriquece, lo hace más complejo y permite que se lleve a cabo contando con mayores elementos de juicio.

Entonces, lo que podemos ver es que las fuerzas del pasado aparecen permanentemente como representaciones sociales. Parte de la labor de la historia consiste en evitar que esas fuerzas se endurezcan en la mitología, que caigan en la nostalgia del encanto por el pasado, que se descontextualicen y que se ignoren. Y es que el pasado es tanto más poderoso cuando se ignora. Es por ello que se podría decir que la investigación histórica se constituye en el gran desamortizador del pasado, en una actividad que lo vuelve a llevar a las personas y a la vida. 


\section{PREGUNTAS}

HERMES TOVAR: Sobre la base de las anteriores exposiciones yo quisiera preguntarle a los panelistas si no se está sobre enfatizando lo relativo a la historia de la cultura. Víctor ha hablado de la cultura del no, Adolfo ha hablado de la identidad suprimida y Jorge Orlando del mestizaje negado y han centrado sus exposiciones sobre estos aspectos. Esto me coloca en una situación un tanto dramática, porque he sido un gran defensor de la historia económica e insisto en la necesidad de impulsarla. Pienso que la historia económica, que también ha sido desterrada de los estudios de la historia colonial, contribuiría al esclarecimiento de los problemas culturales. Uno ve en Colombia un acentuado interés por la historia de la cultura, pero no se ven obras que realmente profundicen en este campo. Uno se podría preguntar si no se trata de un problema de método. Si la vía de la historia económica no facilita el acceso a esos problemas que plantea el análisis de lo cultural, para hacer posible profundizar y aprehender problemas tan trascendentales como el de la cultura del no, el de la identidad suprimida y la del mestizaje negado.

ADOLFO MEISEL: Sobre este problema yo creo que lo mismo que se dice sobre la identidad, se puede decir sobre el pasado económico. Cuando se enfrenta cualquier aspecto de la historia económica se encuentran una serie de mitos que se han enraizado en los respectivos estudios y que cuando se revisan no presentan mayor consistencia. Por ejemplo, frecuentemente se hablaba de la hiperinflación de finales del siglo pasado, pero actualmente hay consenso entre los historiadores económicos en señalar que durante la Guerra de los Mil Días no hubo hiperinflación. Se ha establecido que se presentó una inflación que como máximo fue del $400 \%$ anual, que por su magnitud no puede ser calificada de hiperinflación, y que en parte la aplicación de este término al proceso que se dio corresponde a un error de los historiadores tradicionales, quienes confundieron el precio sobre las monedas extranjeras, con la tasa de cambio vigente en la época. La tasa de cambio nunca subió más de cien pesos a uno y los historiadores tradicionales siempre hablan del diez mil por ciento, que era el precio sobre la moneda extranjera y no la tasa de cambio.

El problema de interpretación antes mencionado tiene una importancia enorme, porque lleva a cimentar la percepción de que muchas de las cosas que se han hecho en el terreno económico terminaron en el fracaso. Esa es una constante no sólo en Colombia sino en Latinoamérica. Y cuando se miran detenidamente esos procesos que se han considerado como un fracaso se observa que hay muchos casos que no pueden ser calificados de tales. Por ejemplo, al revisar el proceso de la transición del sistema fiscal de la Colonia a la República, entre 1780 a 1850, uno encuentra que existe cierto consenso en señalar que todo permaneció 
igual hasta 1850; sin embargo, cuando se estudia el período se aprecia que se produjeron unas profundas transformaciones desde el inicio mismo de la República. Ya para 1850, el sistema fiscal era completamente diferente al vigente en la Colonia y era más eficiente, porque reposaba en el impuesto de aduana que era poco costoso para recaudar. El sistema tributario español era poco eficiente, aunque podía ser bueno para los fines de la Corona española de extraer el máximo de recursos para enviarlos a España, lo que se lograba exitosamente en colonias como México. Pero en el caso de la Nueva Granada no sucedía lo mismo, ya que reposaba sobre los monopolios y estos eran económicamente muy ineficientes, porque casi todo se gastaba en la recaudación y el ingreso neto era como máximo de un $40 \%$.

El sistema tributario que se estableció a comienzos del período republicano resultó mucho más eficiente y justo, ya que suprimieron cargas tan onerosas socialmente como el tributo indígena y otros impuestos que introducían grandes distorsiones desde el punto de vista de la equidad. Se suprimieron, por ejemplo, los impuestos a las expoliaciones y muchas cargas fiscales indirectas que afectaban la asignación de los recursos. Es decir, que el proceso de cambio puede considerarse como relativamente exitoso. Sin embargo, en 1850, se afirmaba que todo lo que se había hecho hasta ese momento en materia fiscal había sido un fracaso. Florentino González fue la persona que más contribuyó a difundir esta idea. Pero en general era compartida por todos los que escribieron sobre estos procesos. Pero lo que se había hecho era importante, a pesar de que no era muy vistoso, porque no hubo profundas transformaciones, sino unas transformaciones graduales y en unas condiciones dificilísimas, ya que se presentó una caída de los ingresos tributarios per cápita. Sin embargo, a pesar de esas dificultades se había logrado transformar el sistema tributario sobre la base de mejorías marginales año por año.

Esta tendencia a la "fracasomanía", de la que se habla en los estudios de política económica latinoamericana, es casi una constante en los países del área, en donde se tiende a concluir que a menudo todo termina en el fracaso. Esto se relaciona con la actitud natural de quienes suben al poder de criticar todo lo que se ha hecho antes. Sin embargo, Albert O. Hirschman considera que en América Latina este fenómeno se magnifica, debido al efecto de la marcada dependencia intelectual de la región, que lleva a que se desprecien los esfuerzos locales. Es decir, que hay un ambiente propicio para desconocer los esfuerzos que se han hecho. En la neutralización de esta tendencia, por ejemplo, la historia económica puede jugar un papel importante, al mostrar lo que se ha podido lograr de positivo en determinada gestión económica.

HERMES TOVAR: Sería un poco la cultura del fracaso la que habría que estudiar en la economía; terminamos siempre en la cultura. 
VÍCTOR ÁLVAREZ: Con relación a esta pregunta yo diría que hoy en día, por la forma como he centrado y dirigido mis preocupaciones sobre el desarrollo histórico de Antioquia, no veo que sean claros los perfiles que diferencian los procesos económicos, de los sociales y lo relativo a la cultura y si todo el problema se sintetiza en la cultura. Voy a dar un ejemplo. Al seguir el desarrollo de las cuadrillas de esclavos en el siglo XVII encontré que había un núcleo de ruptura, que mencioné anteriormente en mi conferencia. En 1630 empezó un proceso que podría denominarse de manumisión de esclavos. Se tejó el precio, etc. Eso fue apenas una pista. Siguiendo el desarrollo de la minería algunos estudios precedentes decían que en ese momento había empezado a disminuir la producción minera. Sobre esta base llegué finalmente a construir una noción que me ha servido para entender cómo se quebró un modelo de organización esclavista que funcionaba sobre la minería y se dio paso a la construcción de otra cosa en Antioquia en el siglo XVII.

Pero esa otra cosa tiene unos perfiles más sociales que económicos. Esa otra cosa, lo enuncié aquí son unos libres, es un proceso de ocupación de un territorio que estaba más o menos despoblado, que les empezó a brindar ocasiones de constituirse en propietarios independientes, de aparecer como un sector social distinto al de los ricos propietarios de esclavos o de haciendas o a los esclavos y trabajadores directos. Este sector empezó a "disputarse" la producción aurífera con los dueños de cuadrillas y sobre sus hombros se fundamentó la minería del siglo XVIII. Pero además encontré que esos hombres comían maíz, que era lo mismo que comían los indios, pero que no tomaban vino ni chicha. Prepararon versiones propias del guarapo y de los aguardientes. Sus tasas de ilegitimidad en los libros parroquiales fueron mucho más altas que las de los poquitos indios que quedaban, que las de los negros o que las de los blancos. Aproximadamente de cada 10 que nacían 7 eran ilegítimos, en las dos versiones, o hijos naturales o hijos bastardos, es decir de matrimonios prohibidos, porque eran de quienes no se habían casado y eso ya tiene como unos perfiles sociales.

Simultáneamente me atreví a construir una hipótesis que he escrito. Esa mayoría de hombres tuvo un juego de relaciones económicas distintas. No eran las que primaban entre los peones de las haciendas del oriente colombiano, ni entre los indios de los resguardos del sur. Son unos señores que desde el siglo XVII fueron al mercado. Llevaban cosas, vendían, compraban, negociaban, estaban al tanto de los precios, calculaban y no eran sólo dos o tres, sino la mayoría de la población. Además encontré otro hecho económico y social. El modelo "colonial" del rico propietario de tierras se quebró también en el siglo XVII. En 1660 había en el valle de Aburra un señor del cual he hablado como en 50 trabajos, Gómez de Salazar, que tenía una hacienda en ese valle con 3.600 cabezas de ganado vacuno y más de 1.000 caballos; era la más grande que nunca ha habido en manos de alguien en Antioquia. Y eso se descompuso y no se vuelve a encontrar nada que se parezca a eso en el siglo XVIII. 
Cuando a comienzos del siglo XIX haya quienes consigan 164.000 hectáreas no era, como algunos se lo imaginan, para concentrarla propiedad, sino unos comerciantes, para hacer un negocio que hoy se llama parcelar. Además, desde el siglo XVIII el modelo de organización de esa sociedad no ha sido el control sobre los medios de producción, por lo menos para el sector rural. La preeminencia de los grupos de élite ha estado en la circulación y no en la propiedad de los medios de producción.

Esa realidad indica que ahí hay unos perfiles económicos, otros sociales y obviamente otros culturales. No dudo que esa percepción que encontramos registrada desde comienzos del siglo XIX, de que los antioqueños son aptos para los negocios, que les gustan, que son tumbadores y mercachifes etc., nació allá en esa sociedad. Si cada quien tenía que ir al mercado a cambiar, vender y comprar, tenía que aprender a moverse en ese juego de relaciones. No es el patrón de la hacienda el que le administra los tabacos, ni las camisas, ni las herramientas, ni trabaja por el salario del patrón. Trabajaba, producía unos recursos y salía al mercado a ver qué hacía con ellos, los cambiaba y buscaba cambiarlos en las mejores condiciones. No se necesitaban genes judíos o vascos para hacerlo. Y entonces esto ya va conduciendo a los territorios de la cultura. Se vuelve racista. Sí, son racistas contra los negros. Son racistas contra los indios y ahora contra los chocoanos y sinuanos. Sobre la base de estas experiencias investigativas, repito, no sé establecer con claridad si eso era pura cultura, economía o sociedad. Para mí eso es como un enredo que no puedo descifrar.

JORGE ORLANDO MELO: Sobre ese punto yo diría que la separación entre la economía y la cultura no es realmente muy fácil de manejar y que de todas maneras nada de lo que yo dije tiene ver con la idea de que haya que dejar de lado los estudios históricos frente a los económicos. Pienso que los estudios económicos son centrales, que para nosotros la economía del pasado es un asunto de cultura y que en el pasado también las relaciones entre distintos elementos de la vida cotidiana eran demasiado intrincadas para separarlos y no se puede entender ninguno de los asuntos de cultura, como por ejemplo el mestizaje, si se separan; si no se entiende también cómo funcionaba la vida económica. De manera que el estudio económico sigue siendo central para comprender el desarrollo de esa sociedad.

FERNANDO NEIRA: Mi pregunta cubre en realidad como tres preguntas. En primer lugar quisiera saber si a raíz de esas explicaciones históricas que se construyen con base en los modelos anteriores ¿se podría decir que uno de los principales problemas de los estudios historiográficos pasados y muchos de los actuales se deben a las tendencias historiográficas de los que los han emprendido? ¿Es un problema de historiadores o ha sido un problema de instituciones políticas que han frenado los procesos de investigación .5 En segundo lugar, desde esta perspectiva, ¿qué estrategias 
interpretativas se requieren para que los nuevos diseños de investigación histórica sean fructíferos? Por último, ¿qué papel jugarían los nuevos historiadores dentro del desarrollo de estas perspectivas investigativas que se abren?

MARTA HERRERA ÁNGEL: Me ha parecido muy interesante todo este llamado de atención sobre el problema del mestizaje. Me preocupa un poco -y la pregunta va dirigida en ese sentido- que al partir la percepción de este problema sobre la base de la trilogía negro-indio-blanco se dificulta la comprensión de la diversidad regional. Esto por cuanto se parte de tres grupos como muy homogéneos y un fenómeno que aparece muy temprano en la Colonia es la diversidad regional. Me pregunto qué tanto tiene que ver con esa variedad, el hecho de que los habitantes de América no fueran solamente indios, sino que fueran Muiskas, Zenúes, Guambíanos y que incluso dentro de culturas relativamente homogéneas hubiera subgrupos. Por ejemplo entre los Muiskas estaban los del Zipazgo, los del Zacazgo y los grupos independientes. ¿№ estará este fenómeno relacionado con la configuración regional, tal como lo planteo el profesor Jaime Jaramillo Uribe, y se está olvidando un poco?

JORGE ORLANDO MELO: La última inquietud la comparto completamente. La idea de que no puede haber estudios de mestizaje hoy en Colombia que no estén ligados de todas maneras a la perspectiva regional. Es más, así como se ve en ese ejemplo sobre el mestizaje, un ejemplo, igualmente válido tendría que hacerse con el problema de la concreción de lo regional, que es tan prioritario y tan importante en el caso colombiano.

Volviendo atrás, a las preguntas anteriores, no vi claramente cuál era el problema al que se hacía referencia. Las investigaciones que se han hecho en el país en estos años responden a la calidad de las metodologías utilizadas y a la capacidad global de los historiadores que las han hecho, con resultados más o menos buenos, más o menos pobres, más o menos medianos. En términos generales lo que han hecho los historiadores colombianos en estos años en el país, no es para que los consideremos los grandes genios de la cultura latinoamericana, pero tampoco para que los veamos como unos parias que realmente no hicieron mayor cosa. Se ha hecho un trabajo importante, significativo, productivo, valioso con defectos, que se han discutido precisamente en los debates entre los historiadores. Tiendo a pensar que comparados con otros sectores de la producción científica colombiana, es un grupo que ha estado por encima de la media, un poco mejor que las otras en cuanto a su productividad y a su capacidad de ser leídos, de su impacto en la sociedad y de realmente producir resultados interesantes en términos del conocimiento del pasado.

De manera que habría que reformular la pregunta. Lo que se ha hecho en el país en materia de historia ha dependido mucho de la calidad de los historiadores que ha 
habido y de que han estado relativamente al día. Claro, no completamente. Los historiadores colombianos, como toda Colombia, mantienen cierto nivel de aislamiento y el historiador colombiano tiende a no mandar sus artículos al exterior, a no repartirlos y eso no es conveniente. Se debe mantener ese diálogo más abierto que facilita la recepción de mayor información y permite estar más al día.

Pero hay también en la percepción pesimista sobre los resultados de la investigación histórica algo ligado a esas secuencias de fracaso-éxito. Y es que en la historia, como en otras disciplinas, como no hay mucha continuidad, con mucha frecuencia se tiene la sensación de que de pronto se descubre algo muy nuevo. Los historiadores pecamos menos en eso que los demás científicos sociales. En general en las ciencias sociales, es usual que se enuncie el descubrimiento de novedades y, cuando se va a ver, se trata de algo que ya se había dicho. Los historiadores algo leen, se leen unos a los otros y se acuerdan de lo que han leído. Eso mejora la situación, pero hay algo de eso. Hay vicios, hay limitaciones, pero no son demasiado dramáticas en el caso de los historiadores colombianos.

Respecto al papel del Estado, al manejo de las instituciones vinculadas con la investigación histórica, creo que, por una parte, la institución que ha jugado un papel esencial en estos últimos treinta o cuarenta años ha sido la universidad. Por otra parte, trataría de diluir un poco la contraposición Estado - sociedad civil. Es decir, el Estado que ha tenido Colombia es el Estado que la sociedad civil se ha dado y la vida de la Universidad es una vida en la cual han influido obviamente unas políticas estatales, pero que nunca han sido muy específicas sobre el problema de la historia. No se le han marcado o impuesto líneas de investigación a la universidad, no se ha establecido que la historia tenga que ser esto o lo otro. En este sentido su dinámica ha sido más el resultado de la vida interna de la universidad. Ha sido más la historia interna de las universidades lo que ha determinado que cosas muy importantes nunca se hayan hecho. Por ejemplo, nunca se logró crear un instituto de estudios históricos como lo propuso el doctor Jaime Jaramillo desde el año 56 o 57. Están los documentos sobre eso, que también muestran lo que se logró hacer en las universidades.

Es decir que no se perfiló una actitud nacional o una política estatal con relación a una u otra línea histórica, aunque en algunos casos hay algo de eso, si uno va a mirarlo en detalle. En ese sentido se pueden recordar los incidentes de los años 60, cuando Indalecio liévano publicó sus estudios Los Grandes Conflictos Económicos y Sociales de Nuestra Historia en Semana y el doctor Alberto Lleras Camargo aprovechó una celebración del 20 de julio para pegarle una vaciada absolutamente radical. Ahora bien, no se trataba de un enfrentamiento del pueblo contra las oligarquías, eran dos sectores de la oligarquía que se estaban disputando el pasado: el doctor López y el doctor Lleras y eso podía verse como un intento de censura. 
Pero en realidad no era un intento de censurar; era parte de una polémica en la que a veces el Estado ha tomado partido. La tomó un poco en algunos momentos con relación a los textos escolares, que no sólo son influyentes, sino importantes. Recordemos la pelea alrededor de los textos de Salomón Kalmanovitz. Pero fue mayor el escándalo que lo que sucedió en la realidad. Es más, el mismo Estado siguió comprando los textos de Salomón Kalmanovitz y si se mira por debajo de cuerda lo que ocurrió, se observa que el Estado no se frenó. Son eventos que los historiadores tal vez no han contado porque hacen parte de unas memorias todavía muy cercanas, pero que se constituyen en una parte interesante de la historia de la historia en Colombia. Sin embargo, podría plantearse una investigación en torno a ellos, al igual que sería muy interesante que alguien preparara un estudio detallado sobre la relación de la historia con el poder.

VÍCTOR ÁLVAREZ: En esta pregunta siento una preocupación relativa a algo que trajo en mención Adolfo respecto a que cada sociedad, cada momento de la sociedad, uno diría cada generación, tiene una forma de ver el pasado y esa forma de ver el pasado es la que explica que después de 400 o 500 años, se diga que hay que volver a escribir historias de cosas que se han escrito desde ese entonces. Algo así como lo que no hicieron los cronistas del siglo XVII, lo que se les quedó por escribir y nos hace falta escribir. Gracias a eso tenemos la producción historiográfica que tenemos sobre historia colonial y nótese que Jorge Orlando Melo nos enseñó hace muchos años (yo no digo cuántos para que ustedes no sepan qué tan viejos somos) que durante mucho tiempo los estudios históricos giraron sobre las primeras décadas de la colonia o sobre la independencia. Lo demás prácticamente no existía. Es decir que los ensayos históricos hechos por colombianos sobre el pasado colonial giraban sobre la conquista hasta hace cincuenta años y cada uno tuvo una versión distinta, miró una cosa distinta, exaltó una cosa distinta. Hoy tendríamos que decir que lo que hizo una generación de historiadores, llamando la atención sobre unos problemas, fue el resultado de su propia situación, algo de eso puede desprenderse de la reflexión de Jorge. Si nosotros íbamos a cambiar la sociedad, si íbamos a liderar el proceso de transformación radical de esta sociedad, nuestras preocupaciones temáticas, los asuntos a los cuales apuntar y hasta las perspectivas iban dirigidas en ese sentido. No nos interesaba la independencia, pero era que eso era lleno de próceres ya consagrados y había era que construir los dioses otra vez, pero los del otro lado. Era un poco lo que había empezado a hacer Indalecio.

Cada sociedad es sensible a unas cosas y con ello me refiero también a los nuevos historiadores. Yo siento que ellos están preocupados por otras cosas. No se ha despertado entre ellos un sentido de solidaridad colectiva, se mueven mucho en lo puramente individual, no se sienten identificados como grupo, cada uno cree que va a descubrir el mundo sólito y eso está bien. Cada uno va descubriendo un mundo 
desde lo que ahora se denomina la postmodernidad y entonces son otros valores y otras formas. Son más caníbales que nosotros con sus colegas y eso da pautas. Les preocupan los símbolos, las imágenes míticas, las representaciones y entonces uno encuentra planteamientos que sorprenden. Me tocó leer un artículo de un joven historiador en donde se animó a decir que los cronistas y los documentos coloniales se habían hecho para engañar y que como eran para engañar, para hacerle creer a los indios cosas que no eran, se inventaron el cuento de la antropofagia y que no era verdad que hubiera habido antropofagia entre los indios, porque todas esas historias eran puramente simbólicas.

ADOLFO MEISEL: En lo que tiene que ver con la historia económica, ésta está en este momento en un período de transición. En los 70's el interés se centraba en los temas que proponía el marxismo. Eso llevó a muchos historiadores a interesarse por la historia económica. En la medida en que esa influencia ha pasado, se está dando tránsito hacia una historia económica hecha por economistas profesionales. Los historiadores ya no se meten mucho en ese campo, en parte porque cuando lo hacen a veces no manejan los conceptos básicos y construyen, por ejemplo, una tasa de cambio y al confrontarla con los economistas encuentran que esa no es la tasa de cambio y los resultados cambian por completo. Entre los economistas, por otra parte, hay un problema de costo oportunidad que explica por qué no se está haciendo mucha historia económica. Muchos economistas se formaron como historiadores económicos, pero dado que en este momento la remuneración de los economistas calificados en Colombia es relativamente buena, incluso en términos internacionales, no se dedican a la historia económica que ofrece ingresos más reducidos. Por este motivo es importante hacer un esfuerzo en los departamentos de economía para que se fortalezcan las cátedras de historia económica. Por ejemplo, en la facultad de economía de la Universidad de los Andes, la historia económica no la dicta la facultad de economía sino la de historia. En la Universidad Javeriana sólo en 1996 se empezó a dictar el curso de historia económica en la facultad de economía.

Es probable que en los próximos años se consolide la tendencia que se observa actualmente hacia la llamada "Nueva Historia Económica", sobre todo para estudiar el siglo XX, porque hay más estadísticas disponibles. De todas formas ello probablemente no restringirá los estudios a ese período, ya que la historia económica de la Colonia o la del siglo XIX, donde la información susceptible de transformarse en series no es tan abundante, puede trabajarse a través del análisis de la teoría económica, en la medida en que se discuten problemas fundamentales de la economía. Esta tendencia de los economistas a preocuparse por la historia colonial se observa ya en las revistas de "Nueva Historia Económica", como el Journal of Economic History, que publica artículos en los que se discute la historia económica de América durante el período colonial. 
HERMES TOVAR: Muy amables, muchas gracias por acompañarnos hoy aquí. Al doctor Melo, quien dejó sus labores en la Biblioteca Luis Ángel Arango para estar con nosotros. Al profesor Víctor Álvarez que vino de Medellín, también dejando sus clases y a Adolfo que dejó sus responsabilidades del Banco de la República de Cartagena. Al doctor William Jaramillo agradecemos su generosidad por estar con nosotros y a todos ustedes, muchas gracias. 